DOI: https://doi.org/10.33103/uot.ijccce.20.3.5

\title{
Digital PID Control Law Design for Fuel Cell Model based on FPGA Emulator System
}

\author{
Wajdi T. Joudah Al-Rubaye ${ }^{1}$, Ahmed S. Al-Araj ${ }^{2}$, Hayder A. Dhahad ${ }^{3}$ \\ ${ }^{I}$ Control and Systems Engineering Department, University of Technology, Baghdad-Iraq \\ ${ }^{2}$ Computer Engineering Department, University of Technology, Baghdad, Iraq \\ ${ }^{3}$ Mechanical Engineering Department, University of Technology, Baghdad-Iraq \\ Wajdy.t@gmail.com,Email:60166@uotechnology.edu.iq,E-mail:hayder_abed2002@yahoo.comm
}

\begin{abstract}
This paper proposes an off-line adaptive digital Proportional Integral Derivative (PID) control algorithm based on Field Programmable Gate Array (FPGA) for Proton Exchange Membrane Fuel Cell (PEMFC) Model. The aim of this research is to obtain the best hydrogen partial pressure $\left(\mathrm{PH}_{2}\right)$ value using FPGA emulator to design and implement a digital PID controller that track the fuel cell output voltage during a variable load current applied. The off-line Particle Swarm Optimization (PSO) algorithm is used for finding and tuning the optimal value of the digital PID controller parameters that improve the dynamic behavior of the closed loop digital control fuel cell system and to achieve the stability of the desired output voltage of fuel cell. The numerical simulation results (MATLAB) package and FPGA emulator experimental work show the performance of the proposed FPGA-PID controller in terms of voltage error reduction and generating optimal value of the $\left(\mathrm{PH}_{2}\right)$ control action without oscillation in the output and no saturation state when these results are compared with other control methodology.
\end{abstract}

Index Terms - Fuel Cell, FPGA, PID Controller, Particle Swarm Optimization.

\section{INTRODUCTION}

Recently, the world is directed towards alternatives sources of energy that exists as a result of pollution in our planet and climate change, as well as the diversity of sources that are sought by major energy companies. Therefore, many researchers are focusing on fuel cell because of their advantages as they operate as the battery or internal combustion engines, but with high efficiency up to two or three times [1], [2]. Although discovered in the $18^{\text {th }}$ century, it began to highlight on fuel cells in the 1960s when NASA was used in spacecraft launched into space [3]. The principle of mechanism working for the fuel cell is simply the production of electrical energy because of the chemical reaction. There are many ways in which fuel cells are classified, the most important of which is by electrolyte and the most important types are Alkaline Fuel Cell (AFC), Phosphoric Acid Fuel Cell (PAFC), Molten Carbonate Fuel Cell (MCFC), Solid Oxide Fuel Cell (SOFC) and Proton Exchange Membrane Fuel Cell (PEMFC) [4], [5]. The mostly used fuel is hydrogen as in PEMFC or carbon monoxide and natural gas. The anode is supplied with hydrogen and the cathode with oxygen in the fuel cells, the catalyst separates the hydrogen atoms in anode into protons and an electron, the membrane allows only the hydrogen protons Cross to the cathode. The hydrogen electrons moving from outside the cell to the cathode. The chemical reaction occurs in the cathode between hydrogen atoms and oxygen with the help of the catalyst and produces water and heat. The electrical energy produced as the resulting of the hydrogen electrons through the electrical circuit, which generates a DC voltage. A single fuel cell produces approximately 1.23 volt, when the load is applied 0.6 to 0.7 volt [6]. The fuel cells can produce an electric energy that may reach MW by forming it in a serial or parallel manner for obtaining the necessary energy. Grouping of cells is called a stack. In this research, there is a focus on the PEMFC because its great advantages 
and the most important one is that it can work in room temperature with low pressure and fast response quiet, does not have moving parts, and can be applied in portable applications, the domestic power or power stations [2], [6], [7]. The fuel pressure, temperature, humidity and current applied are factors affecting the fuel cell and making the fuel cell system generation non-linear dynamical behavior [8]. The sensitivity of this system is very high because of its high current and low voltage, so it needs a controller that can minify this sensation by making the external voltage constant. Therefore, to obtain greatest energy generation and more efficiency, many researchers resorted to use different types of linear controllers for tracking output voltage of fuel cells. Because of many variation parameters of fuel cell led to the nonlinear dynamical performance output voltage and the process of controlling inaccurate.

So that, many other researchers have worked to use nonlinear methods and techniques to solve the variation parameters problems in the fuel cell such as sliding mode controller [9] and adaptive backstepping controller [10]. While other researchers have resorted to using artificial intelligence algorithms to understand the phenomena involved in the generation process of fuel cells such as fuzzy logic control [11], [12], fuzzy-PID controller [13], neural networks [2], [7], [14], [15]. In addition, many types of intelligent evolutionary algorithms have been used to build the modelling of PEMFC and controlling it. Genetic algorithm [16], particle swarm optimization algorithm [17], firefly optimization algorithm [18] and hybrid Chaotic Particle Swarm Optimization with Firefly algorithm [7].

The motivation for this research is to enhance the dynamical performance of the output voltage of a real-time nonlinear fuel cell model during a variable load current applied by providing the feul cell with the best value of the control action $\left(\mathrm{PH}_{2}\right)$.

Therefore, the contribution of this work is to design and implement digital PID control law to achieve the following properties:

- A smooth value of the hydrogen partial pressure control action $\left(\mathrm{PH}_{2}\right)$ which is generated using MATLAB simulation based on the proposed design of the digital PID control law.

- An adaptive control algorithm based on off-line PSO technique is used in order to stabilize the output voltage of the fuel cell as well as to fast track the desired voltage with minimum tracking voltage error during changing the load current.

- A FPGA Spartan-3E xc3s500e-4fg320 board with Verilog hardware description language for design testing are designed, implemented and verified the digital FPGA-PID control law.

- A proposed continuous control law equation is replaced by the proposed an adaptive digital control law equation in real time MATLAB environment system.

This paper is organized as follows: Section I, explains the nonlinear fuel cell mathematical model. Section II, describes the proposed digital PID control law. Section III, shows the effectiveness of the digital controller through numerical simulation results in MATLAB. Section IV, illustrates the experimental work based on Xilinx Spartan-3E Starter Kit. Finally, conclusions of this research are given in section $\mathrm{V}$.

\section{NONLINEAR FUEL CELL MODEL DESCRIPTION}

In general, PEM fuel cells consists of three main components: anode, cathode, and electrolyte [19]. Anode typically displays a catalyst containing platinum or platinum, and cathode a platinum catalyst. The electrolyte is a thin, solid polymeric sheet. The reactions of a PEMFC are shown in Fig. (1), when hydrogen feeds to an anode side the catalyst causes hydrogen atoms to become $\left(\mathrm{H}^{+}\right)$ions (protons) and releases their electrons as in (1).

$$
2 \mathrm{H} \longrightarrow 4 H^{+}+4 e^{-} \quad \text { anode }
$$


The electrolyte membrane will only allow hydrogen protons to pass throws from the anode side to the cathode side as shown in Fig. 1. The reaction in the cathode occurs as a result of the reaction of hydrogen ions entering from the electrolyte to the cathode side with electrons from the outer circuit and oxygen supply from air the cell and produces water as in (2).

$$
4 \mathrm{H}^{+}+4 e^{-}+4 \mathrm{O}^{+} \longrightarrow 2 \mathrm{H}_{2} \mathrm{O}+\text { heat } \text { cathode }
$$

Under normal operation conditions, a single cell produces from 0.5 to 0.9 volts since a higher power is needed and a number of cells are connected serially and as needed called a stack and a stack arrangement can be up to hundreds of kilowatts. Generally, the polarization curve is used to express the performance of the whole cell and shows highly non-linear properties between voltages and current [2], [7]. The output voltage of a single cell can be defined as follows:

$$
V_{\text {cell }}=E_{N}-V_{\text {ohm }}-V_{\text {act }}-V_{\text {con }}
$$

Where, $\mathrm{E}_{\mathrm{N}}$ is the thermodynamic potential of the cell and it represents reversible voltage in volt. $\mathrm{V}_{\text {ohm }}$ is the ohmic voltage drop in volt, a measure of the ohmic voltage drop associated with the conduction of the protons through the solid electrolyte and electrons through the internal electronic resistances [12].

$\mathrm{V}_{\text {act }}$ represents the voltage drop due to the activation of the anode and of the cathode in volt. $\mathrm{V}_{\text {con }}$ represents the voltage drop resulting from the concentration or mass transportation of the reacting gases in volt [12]. Table I. shows the physical parameters of PEMFC that are taken from [2], [7].

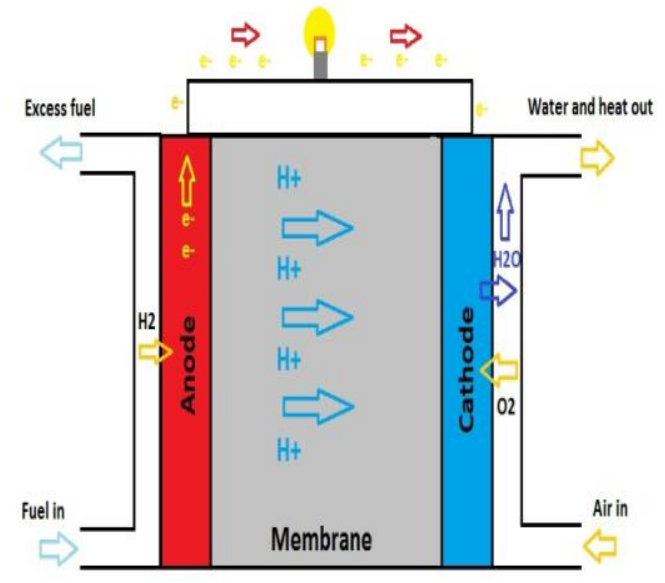

FIG. 1. THE PRINCIPLE WORKING OF PEMFCS, [2].

TABLE I. THE PHYSICAL PARAMETERS OF PEMFC [2], [7].

\begin{tabular}{|c|c|c|c|c|c|}
\hline Parameters & Values & Units & Parameters & Values & Units \\
\hline Ncell & 32 & & $\alpha_{3}$ & $-706^{*} 10^{-5}$ & V. $\mathrm{cm}^{2} /$ Kelvin. mol \\
\hline $\mathrm{T}$ & 298 & Kelvin degree & $\alpha_{4}$ & $1.93 * 10^{-4}$ & $\mathrm{~V} /$ Kelvin. Amp \\
\hline $\mathrm{A}$ & 64 & $\mathrm{~cm}^{2}$ & $\mathrm{~J}$ & 0.0073 & $\mathrm{~mA} / \mathrm{cm}^{2}$ \\
\hline $\mathrm{L}$ & $178 * 10^{-6}$ & $\mathrm{~cm}$ & $\mathrm{Jmax}$ & 0.469 & $\mathrm{~mA} / \mathrm{cm}^{2}$ \\
\hline $\mathrm{PH}_{2}$ & $1-5$ & $\mathrm{Atm}$ & $\Phi$ & 23 & \\
\hline $\mathrm{PO}_{2}$ & 0.2 & $\mathrm{Atm}$ & $\alpha_{1}$ & 0.948 & $\mathrm{~V}$ \\
\hline $\mathrm{Rc}$ & 0.0003 & $\Omega$ & $\alpha_{2}$ & -0.00312 & $\mathrm{~V} / \mathrm{Kelvin}$ \\
\hline$\beta$ & 0.0169 & $\mathrm{~V}$ & & & \\
\hline
\end{tabular}

EN also called the reversible voltage of the cell and can be found out [2], [7], [12].

$$
E_{N}=1.229-0.85 * 10^{-3} *(T-298)+4.3085 * 10^{-5} *\left(T\left(\operatorname{In}\left(P_{H 2}\right)+0.5 \operatorname{In}\left(P_{O 2}\right)\right)\right)
$$


Where $\mathrm{PH}_{2}$ and $\mathrm{PO}_{2}$ is the partial pressure of hydrogen and oxygen in atom respectably. Moreover, $\mathrm{T}$ is fuel cell temperature in Kelvin.

The voltage of the ohmic loss can be determined by using the equation below [7], [12], [16].

$$
V_{\text {ohmic }}=I .\left(R_{c}+R_{m}\right)
$$

Where, I represents cell loaded current. Rc denotes proton resistance $(\Omega)$ constant value [2], [7]. Rm $=$ the electron flow equivalent resistance $(\Omega)$ and can represent as in (6) [7], [19].

$$
R_{m}=\frac{L * \rho_{m}}{A}
$$

Where, $\mathrm{L}$ is thickness of the polymer membrane $(\mathrm{cm})$. A is an active cell area $\left(\mathrm{cm}^{2}\right) . \rho_{m}$ denotes membrane specific resistivity $(\Omega . c m)$ which computed as following expression [2], [7], [19]:

$$
\rho_{m}=\frac{181.6\left[1+0.03\left(\frac{L}{A}\right)+0.062\left(\frac{T}{303}\right)^{2}\left(\frac{L}{A}\right)^{2.5}\right]}{\left[\varnothing-0.634-3\left(\frac{L}{A}\right) e^{\frac{4.18(T-303)}{T}}\right]}
$$

$\emptyset$ is the ratio of the number of water moles for each sulfonic group in the membrane. $V_{\text {con }}$ can be expressed as follows [2], [7], [19]:

$$
V_{c o n}=-\beta \operatorname{In}\left[1-\frac{J}{J_{\max }}\right]
$$

$\beta$ is parametric coefficient. $J$ is the current density that passes through the cell $\left(\mathrm{amp} / \mathrm{cm}^{2}\right) . J_{\max }$ is the maximum current density that passes through the cell $\left(\mathrm{amp} / \mathrm{cm}^{2}\right)$, can be expressed as follows [19]:

$$
J_{\max }=\frac{I_{\max }}{A}
$$

$V_{a c t}$ is the voltage drop (V) due to the activation of the anode and can be expressed as follows [2], [19]:

$$
V_{a c t}=\alpha_{1}+\alpha_{2} \cdot T+\alpha_{3} \cdot T \cdot \operatorname{In}\left(C_{O 2}\right)+\alpha_{4} \cdot T \cdot \operatorname{In}(I)
$$

Where, $\alpha_{i}$ are parametric coefficients. $C_{O 2}$ is effective concentration of oxygen $\left(\mathrm{mol} / \mathrm{cm}^{3}\right)$ and can be calculated as follows [2], [7], [19]:

$$
C_{O 2}=\frac{P_{O 2}}{5.08 * 10^{6} *\left(e^{\frac{-498}{T}}\right)}
$$

The total output voltage of the stack can be determined by the (12) [2], [7].

$$
V_{F C}=N_{\text {cell }} V_{\text {cell }}
$$

Where, Ncell symbolizes the number of stack.

The (13) is used to determine the overall output power (in watt) from the stack:

$$
\text { Power }_{F C}=I V_{F C}
$$

To study the characteristic of the fuel cell "voltage against load current" at temperature $25 \mathrm{C}^{\circ}$ and partial pressure of hydrogen and oxygen are 1 and 0.2 Atm respectively is shown in Fig. 2 that seen the output voltage of the fuel cell against a variable load current.

To study the effect of the losses voltage for the fuel cell, the polarization curve is shown in Fig. 3. To understand the effect of variation the hydrogen partial pressure from range 0.2 to 1 Atm with constant oxygen partial pressure is $0.2 \mathrm{Atm}$ of the fuel cell at maximum load current is 30A is shown in Fig. 4. To analyze the effect of temperature variation of the fuel cell with constant partial pressure of hydrogen and oxygen and with maximum load current is $30 \mathrm{~A}$, as shown in Fig. 5. 


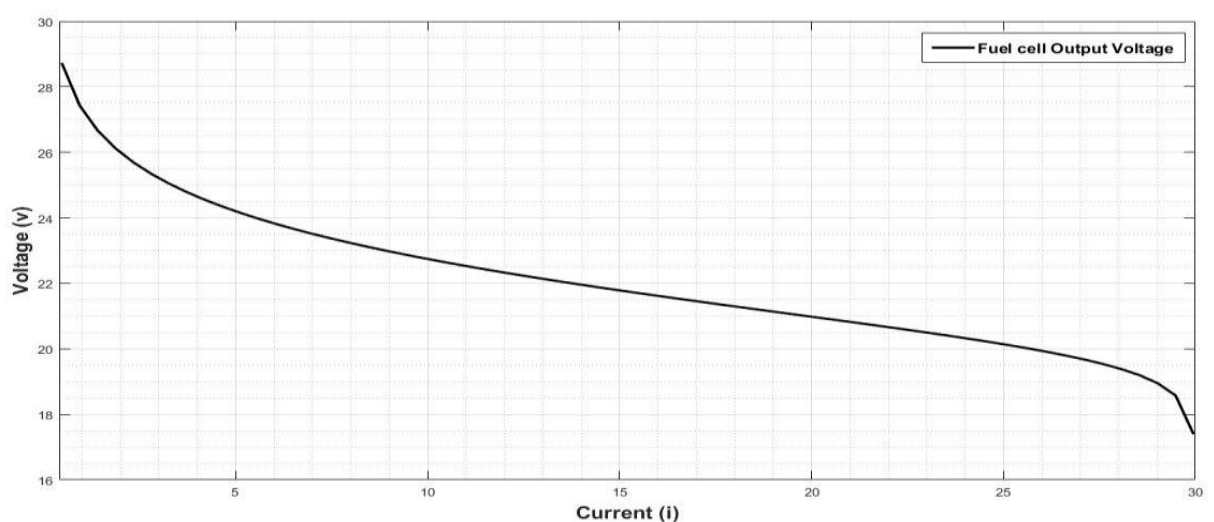

FIG. 2. LOAD CURRENT VARIABLE AGAINST FUEL CELL OUTPUT VOLTAGE

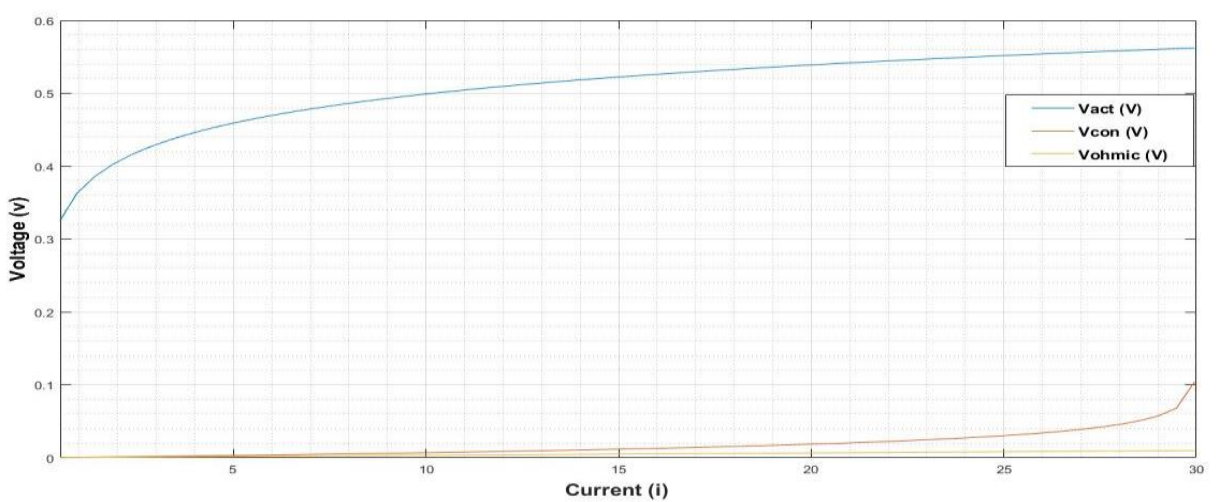

FIG. 3. VARIABLE LOAD CURRENT AGAINST FUEL CELL DROP VOLTAGE .

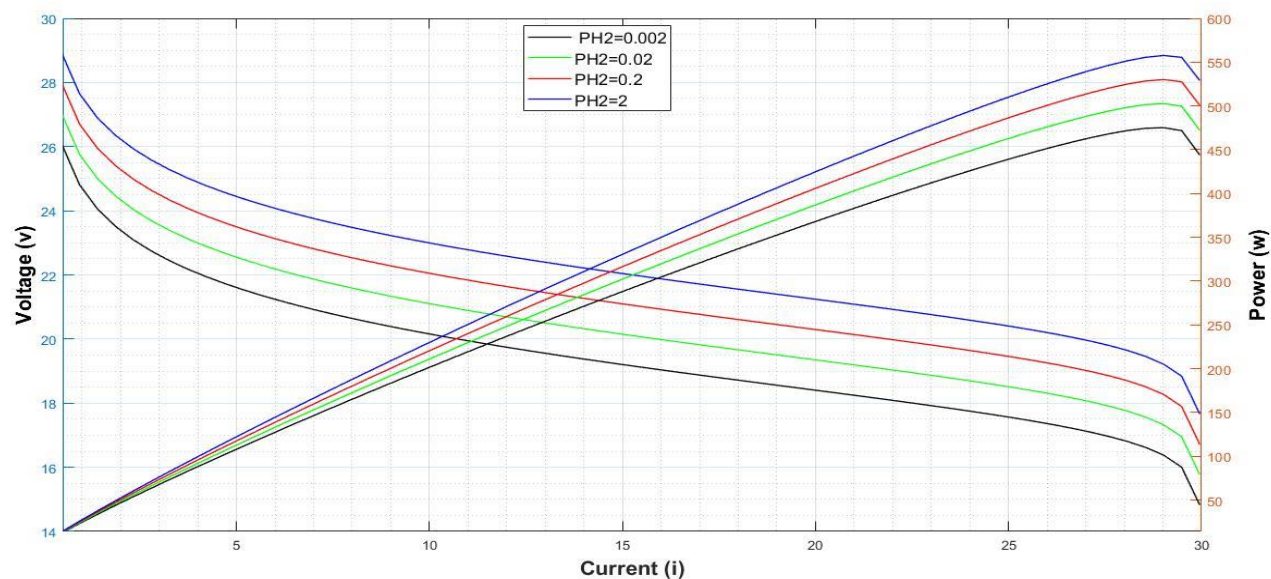

FIG. 4. VARIATION PARTIAL PRESSURE OF HYDROGEN FOR FUEL CELL. 


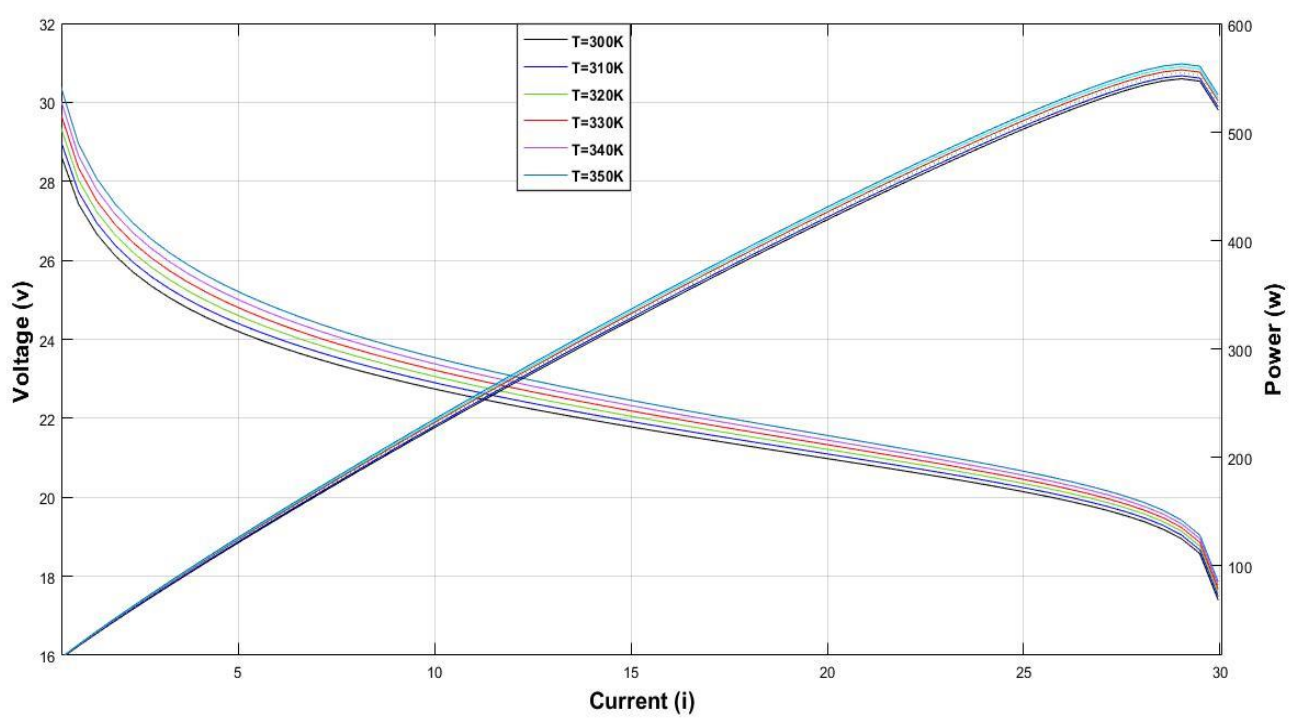

FIG. 5. THE EFFECT OF TEMPERATURE VARIATION OF THE FUEL CELL.

\section{DIGITAL PID CONTROLLER DESIGN}

In industrial applications, the traditional PID controller is considered one of the most popular control devices in terms of its simplicity and easy to understanding the structure, which consist of three terms proportional, integral and derivative. To solve the tuning limitation in the traditional PID controller, the proposed an adaptive digital PID controller with PSO off-line tuning parameters are used, which led to have a high dynamical characteristic and strong adaptation performance [20]. Fig. 6; shows the proposed controller which has the ability in terms of generating optimal or near optimal control parameters that will obtain smooth and best control action in order to fast track the desired output voltage of the fuel cell system as well as to reduce the voltage error [21].

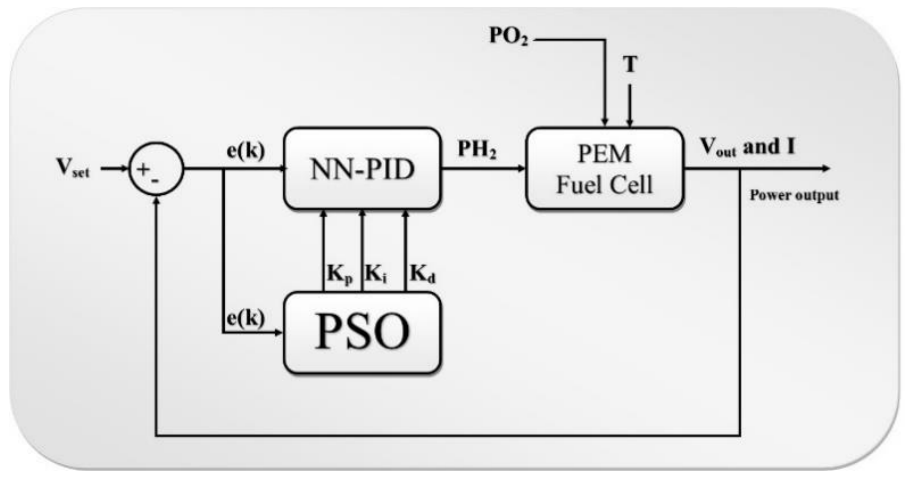

FIG. 6. THE PROPOSED CONTINUOUS PID CONTROLLER FOR FUEL CELL SYSTEM.

In the time domain, the continuous PID controller [20], [21].

$$
u(t)=k_{p} e(t)+k_{i} \int_{0}^{1} e(t)+k_{d} \frac{d e(t)}{d t}
$$

Where, $\mathrm{k}_{\mathrm{p}}$ is the proportional gain, $\mathrm{k}_{\mathrm{i}}$ integral gain, $\mathrm{k}_{\mathrm{d}}$ is the derivative gain, and $\mathrm{e}(\mathrm{k})$ error signal and $\mathrm{u}(\mathrm{t})$ is the controller action.

There are three proposed steps for designing and implemention of the proposed digital PID controller in FPGA as follows: 
The first step is digitized the continuous control law PID as in (14) based on the backward z-transform, the digital control law become as in (15).

$$
P H_{2}(k)=K_{p} e(t)+K_{i}(e(k)+e(k-1))+K_{d}(e(k)-e(k-1))+P H_{2}(k-1)
$$

The objective function in the off-line tuning is used a mean square error function in order to evaluate the error between the desired output and the actual output of the fuel cell as in (16) [21].

$$
E=\frac{1}{p} \sum_{i=1}^{p}\left(e\left(t^{k}\right)\right)^{2}=\frac{1}{p} \sum_{i=1}^{p}\left(V_{d e s}\left(t^{k}\right)-V_{F C}\left(t^{k}\right)\right)^{2}
$$

Where, $\mathrm{k}$ : sample, $\mathrm{t}$ : iteration, $p$ : is the population number. e : is the error at each iteration. $V_{F C}$ : is the fuel cell output voltage at each iteration. $V_{d e s}$ : is the desired output voltage at each iteration.

$\mathrm{KP}, \mathrm{Ki}$, and $\mathrm{Kd}$ are control gain parameters which are obtained and tuned using the PSO algorithm in order to make the transient state of the control action is fast that leads to reach the desired output voltage smoothly without voltage error, no overshoot, and no oscillation in the output voltage response of the fuel cell.

The second step is PSO algorithm, James Kennedy and Russell C. Eberhard in 1995 were first described the PSO based on social-psychological principles as a stochastic algorithm inspired by simulation of social behaver such as birds flocking and fish schooling to solve real optimization problems [17]. The PSO is a direct search method which derivative-free that depends only on the evaluation of the cost function. PSO is an abbreviation of Particle Swarm Optimization where features fast, easy to implement, doesn't need gradient method to optimized function and has a few parameters to adjust [7], [22].

The PSO tuning algorithm is used to find digital PID weights ( $\mathrm{KP}, \mathrm{Ki}$, and $\mathrm{Kd}$ ) at minimum cost function of Mean square error (MSE) for the closed loop controller of PEMFC. According to simple mathematical formulas, the particles moving in the search-space over the particle's position and velocity. The particle's movement influenced by its local best position which is guided toward in the search-space to the best-known positions, better positions are found updated by other particles. So the best solutions expected the swarm move toward. The position and velocity of the particles at each time step are updated according to the equations. The step of PSO can be explained in following steps: Define the input-output parameters of the fuel cell such as the $\left(\mathrm{PH}_{2}\right)$ partial pressure of hydrogen, the $\left(\mathrm{PO}_{2}\right)$ partial pressure of oxygen, the fuel cell operating temperature (T), the cells numbers (Ncell), the maximum output current of the fuel cell (Imax), and the cell current of fuel cell (Icell); The maximum number of iterations and initialize randomly values of particles control gains $\left(\mathrm{K}_{\mathrm{p}}, \mathrm{K}_{\mathrm{i}}\right.$, and $\left.\mathrm{K}_{\mathrm{d}}\right)$ "proposed between (0 to 1)"; Find the personal best for each particle digital PID parameters according to (15) first iteration the personal best it same the random initialize numbers where $t$ for iteration and $i$ particle number

$$
P_{\text {best }, i}^{t+1}=\left\{\begin{array}{l}
\mathrm{p}_{\text {best, }}^{t} \text { if } f\left(x_{\mathrm{i}}^{\mathrm{t}}\right)<f\left(x_{\mathrm{i}}^{\mathrm{t}+1}\right) \\
x_{\mathrm{i}}^{\mathrm{t}+1} \text { if } f\left(x_{\mathrm{i}}^{\mathrm{t}}\right) \geq f\left(x_{\mathrm{i}}^{\mathrm{t}+1}\right)
\end{array}\right.
$$

- Find the Global best for all particles by

$$
G_{\text {best }}=\max \left\{\mathrm{P}_{\text {best }, i}^{\mathrm{t}}\right\}
$$

- $\quad$ Find the velocity for all particles by (19) [17], [22].

$$
v_{\mathrm{i}}^{\mathrm{t}+1}=v_{\mathrm{i}}^{\mathrm{t}}+c_{1} r_{1}^{\mathrm{t}}\left[P_{\text {best }, i}^{\mathrm{t}+1}-x_{\mathrm{i}}^{\mathrm{t}}\right]+c_{2} r_{2}^{\mathrm{t}}\left[G_{\text {best }}-x_{\mathrm{i}}^{\mathrm{t}}\right]
$$

Where, $c_{1}+c_{2}<4$, and $\mathrm{r}_{1}$ and $\mathrm{r}_{2}$ are random values between ( 0 to 1 ).

- $\quad$ Find new position for all particles control gains by [17], [22].

$$
x_{\mathrm{i}}^{\mathrm{t}+1}=x_{\mathrm{i}}^{\mathrm{t}}+v_{\mathrm{i}}^{\mathrm{t}+1} v
$$


- Based on (16) calculate better cost function (mean square error); Update the particles (control gains) velocity and position; Update the iterations counter. Check the stopping criteria is satisfied, then stop and find the best control gain parameters, else loop to the first step.

Fig. 8; shows the off-line flowchart of PSO algorithm that describes the control gain parameters of the digital PID are updated at each iteration in order to obtain the best $\left(\mathrm{PH}_{2}\right)$ control action that will lead to minimize the voltage error between the desired output voltage and PEMFC output voltage model.

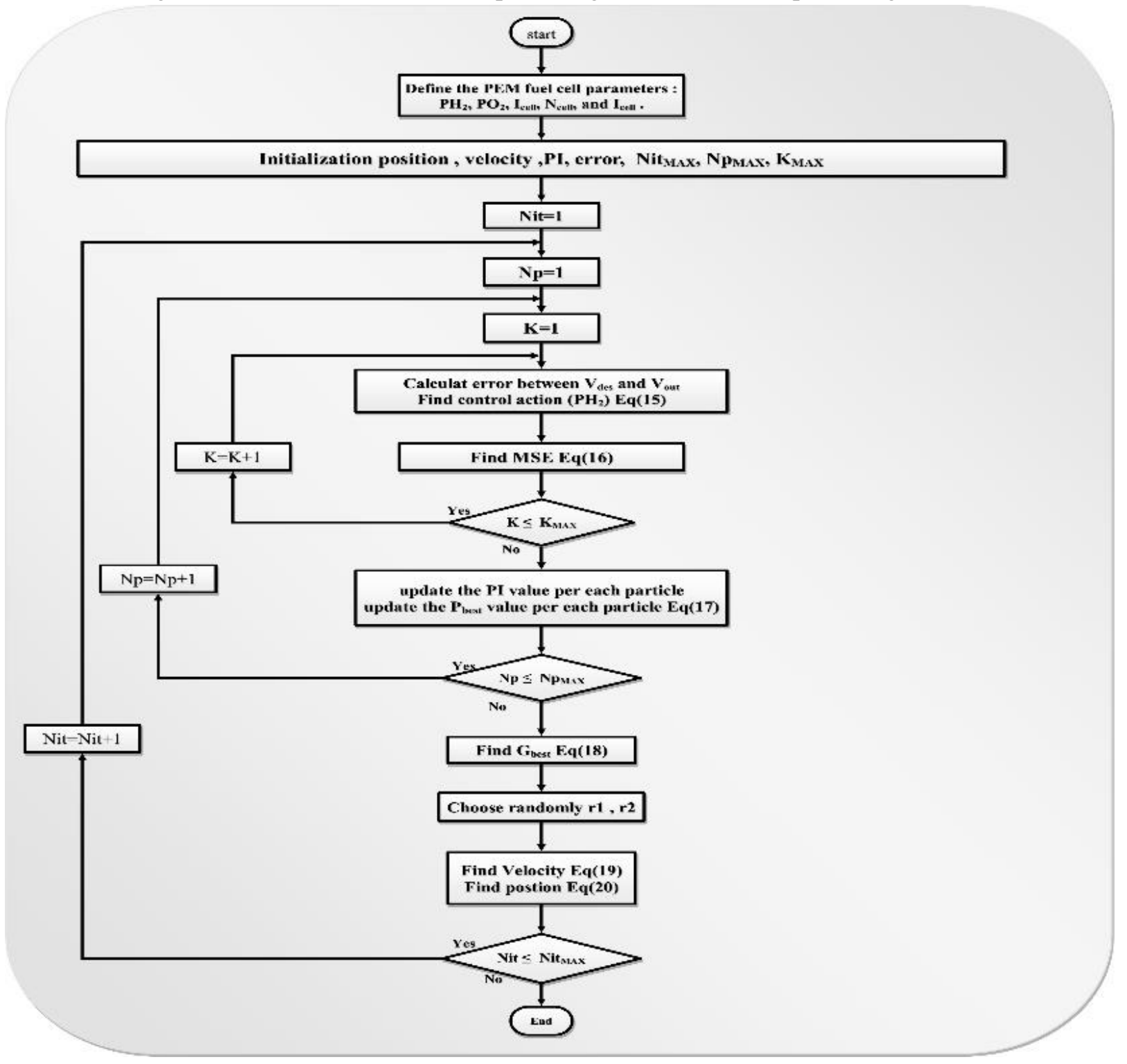

FIG. 8. OFF-LINE PSO ALGORITHM FOR TUNING CONTROL GAIN PARAMETERS.

The third step converted the proposed digital PID controller to the structure of FPGA as shown in Fig. 9; by using ISE package Ver.14.7 based Xilinx development tool in order to design, implement and verify the proposed FPGA-PID controller. One of the important points in the FPGA design, the finite word length. The designer should determine the word length of all ICs will be used. Therefore, the finite word length of the proposed FPGA-PID controller design is sixteen bits [23]-[25] as follows:

One bit for sign; Two bits for integer; Thirteen bits for fraction for all registers, adders/subtractions, and multipliers ICs.

The FPGA-PID controller consists of three modules as follows:

The two's complement arithmetic module; An off-line adaptive digital PID control law module; The control unit module. 
The proposed adaptive FPGA-PID controller needs IC as the overall modules design with control signals as shown in Table. II.

Table II. An adaptive FPGA- PID controller IC components

\begin{tabular}{cccc}
\hline Logic Utilization & Used & Logic Utilization & Used \\
\hline Number of Slices & 124 & Number of multiplayers & 5 \\
Number of Slice Flip Flops & 248 & Number of two's complement & 1 \\
Number of bonded IOBs & 140 & Number of multiplayers & 3 \\
Number of GCLKs & 1 & Number of two's complement & 2 \\
Number of Shaft register & 10 & Number of And gates & 2 \\
Number of comparators & 4 & Number of Nor gates & 3 \\
Number of Or gates & 2 & Number of Nand gates & 1 \\
\hline
\end{tabular}

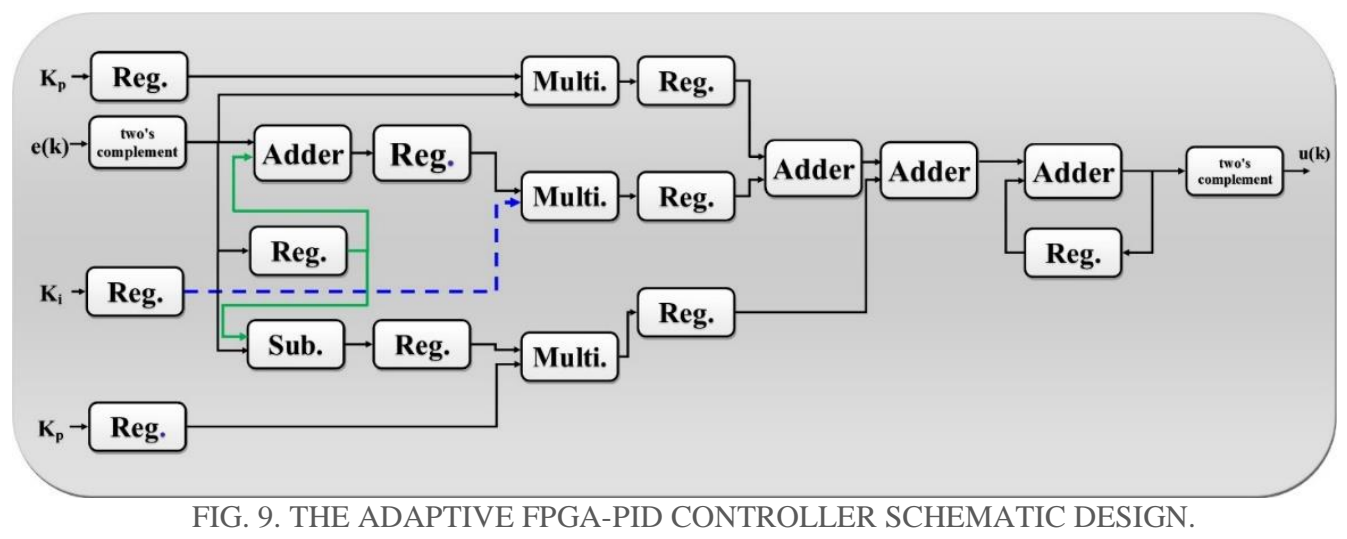

III. MATLAB SIMULATION RESULTS

The MATLAB numerical simulation package is used to carry out the proposed digital PID controller for the fuel cell system as shown in Fig. 6; and used the physical parameters of the fuel cell as shown in Table I with (15) to (17). The off-line PSO algorithm is used to find and tune the weights of the adaptive digital PID controller. Fig. 10; shows the investigating of best number of particles and number of iterations against the mean square error. The proposed criteria that used to find the best number of the particles and the numbers of iterations as follows:

Step 1: Start the iterations number at 20.

Step 2: Take particles number is 5.

Step 3: Evaluate the MSE fuction at 125 samples and save the parameters value.

Step 4: Increase number of the particles by 5, where the maximum number of particles is 50 then go to step 3.

Setp 5: Increase number of the iteration by 20, where the maximum number of iteration is 200 then go to step 2.

The parameters of the PSO algorithm is defined in Table III. Based on the best parameters values that are taken from Fig. 10.

TABLE III. PSO ALGORITHM PARAMETERS.

\begin{tabular}{cc}
\hline Parameters & amount \\
\hline Number of Particles & 20 \\
Number of iterations & 100 \\
$\mathrm{c}_{1}$ and $\mathrm{c}_{2}$ are the same value & 1.25 \\
$\mathrm{r}_{1}$ and $\mathrm{r}_{2}$ are random value & Random $(0,1)$ \\
\hline
\end{tabular}




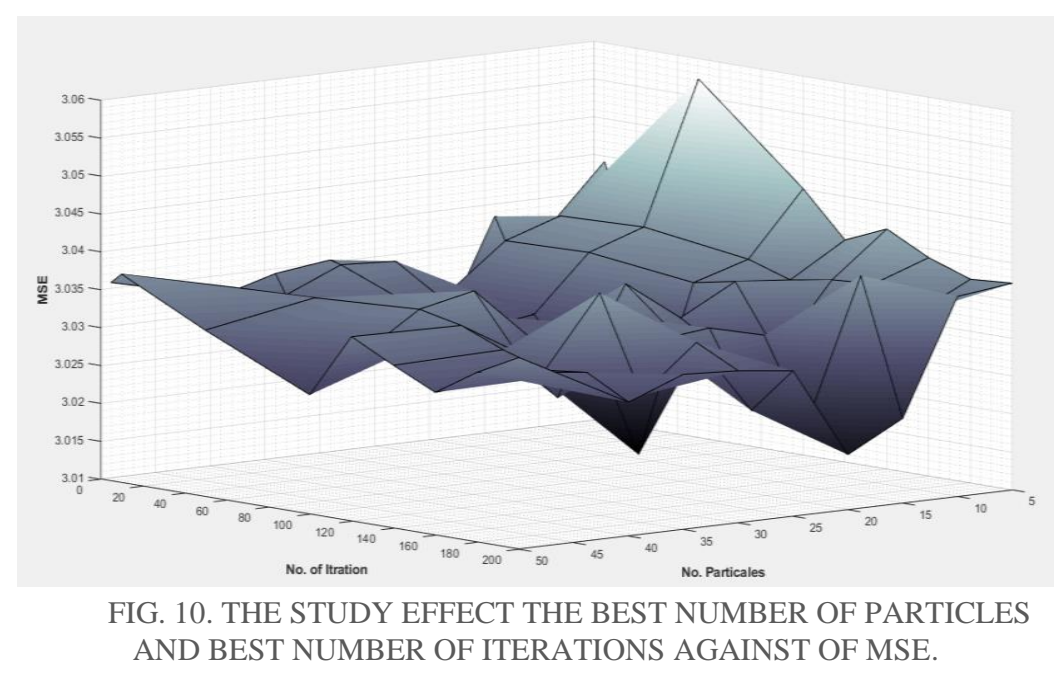

These parameters achieved a convergence to a global optimum of PSO algorithm in terms of minimizing the objective function. To show the effectiveness of the proposed digital PID controller with PSO tuning algorithm for the PEMFC system during 125 samples, the desired output voltage is changed in five phases $(21,22.5,23.5,21.5$ and 22.5)volt with variation load current in five stages as $(15,10,7,15$ and 10$)$ Amp, as shown in Figs. 11-a, b_respectively. The actual output voltage of the fuel cell is the fast response to reach the desired output voltage without overshoots, no oscillation, rising time is equal to $0.92 \mathrm{sec}$ and settling time is qual to $2.33 \mathrm{sec}$ in the transinet state and in the steadt state the error was very small value. Fig. 12; shows the fast response with small swing of the partial pressure $\left(\mathrm{PH}_{2}\right)$ control action of the proposed digital PID controller in order to track the desired output voltage. The best values of the digital PID controller's gain parameters are ( $\mathrm{kp}=0.4409 ; \mathrm{ki}=0.6172, \mathrm{kd}=0.2346$ ) based on minimum mean square error. Fig. 13; shows the off-line PSO tuning algorithm performance index of the proposed closed loop digital PID controller system. To investigate the proposed control methodology is better than another controller in terms of the dynamic state, steady-state error, number of fitness evaluation and the control gain parameters numbers; Table IV. shows the comparison between other types of controller.

TABLE IV. COMPARISON BETWEEN DIFFERENT TYPES OF CONTROLLER.

\begin{tabular}{ccccc}
\hline Type of controller & Over shoots & Steady-State Error & No. of Iterations & No. of weights \\
\hline $\begin{array}{c}\text { Neural Predictive Controller } \\
\text { Reference [2] }\end{array}$ & No overshoot & $\begin{array}{c}\text { Small Error with very } \\
\text { small oscillation }\end{array}$ & 20 & 50 \\
$\begin{array}{c}\text { Neural Inverse Direct } \\
\text { Controller Reference [7] } \\
\text { Proposed Controller }\end{array}$ & Small overshoot & 0 & 45 & 220 \\
\hline
\end{tabular}



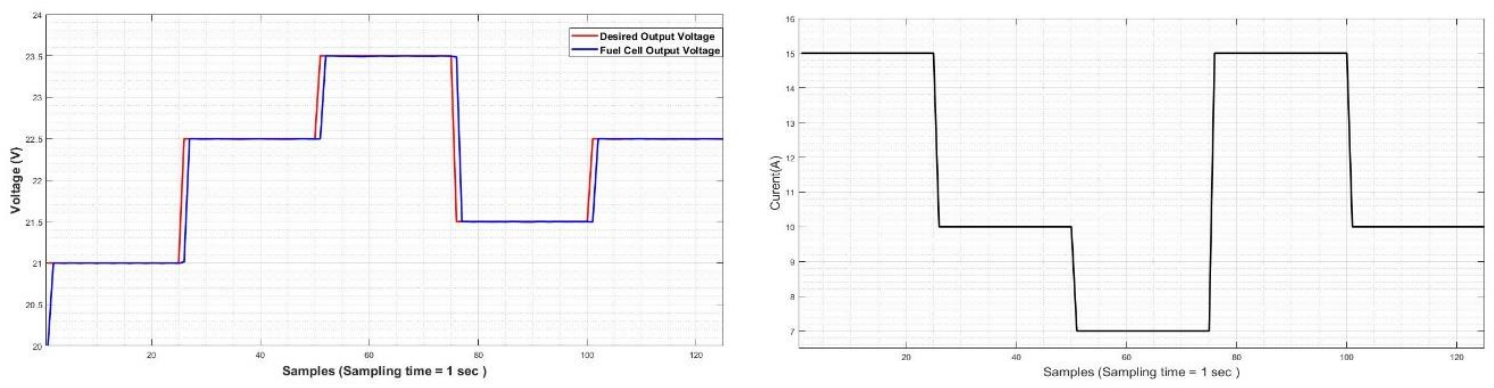

FIG. 11. (a) THE FUEL CELL OUTPUT VOLTAGE; (b) FUEL CELL LOAD CURRENT.

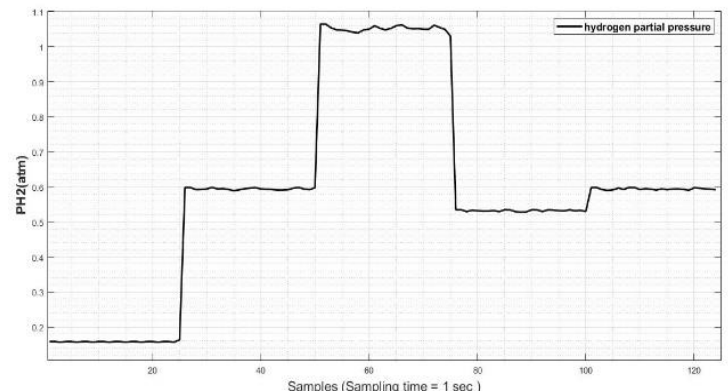

FIG. 12. THE CONTROL ACTION $\left(\mathrm{PH}_{2}\right)$ RESPONSE.

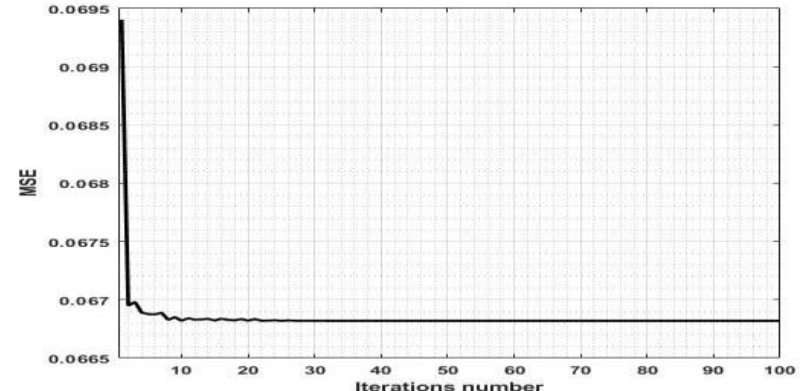

FIG. 13. OFF-LINE PERFORMANCE INDEX.

\section{EXPERIMENTAL WORK}

To carry out the proposed schematic design of the off-line adaptive FPGA-PID controller, as shown in Fig. 9; MATLAB environment system uses the real-time Spartan-3E Starter Kit with device xc3s500e-4fg320 as shown in Fig. 14.

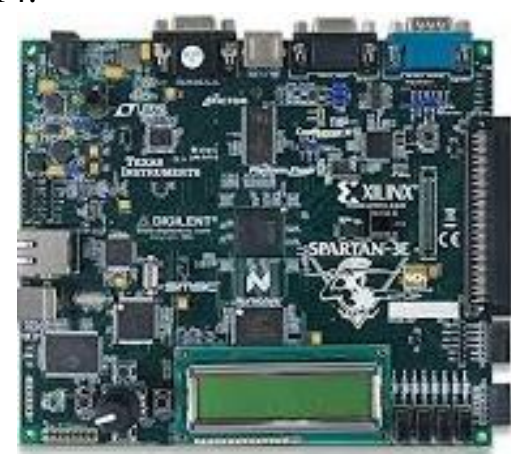

FIG.14.SPARTAN-3E STARTER KIT.

Xilinx-ISE Design Suite 14.7 uses as sequence of operations (synthesize-XST, Implement Design and Generate Programming File) for the proposed controller. Therefore, the design synthesized and implemented successfully as shown in summary report Fig. 15. 


\begin{tabular}{|l|l|c|l|}
\hline \multicolumn{5}{|c|}{ pidnn Project Status } \\
\hline Project File: & fogapidfianle.xise & Parser Errors: & No Errors \\
\hline Module Name: & pidnn & Implementation State: & Placed and Routed \\
\hline Target Device: & xc3s500e-4fg320 & - Errors: & \\
\hline Product Version: & ISE 14.7 & - Warnings: & \\
\hline Design Goal: & Balanced & • Routing Results: & All Sianals Completely Routed \\
\hline Design Strategy: & Xilinx Default (unlocked) & - Timing Constraints: & All Constraints Met \\
\hline Environment: & System Settings & - Final Timing Score: & 0 Timing Report) \\
\hline
\end{tabular}

\begin{tabular}{|c|c|c|c|c|}
\hline \multicolumn{5}{|c|}{ Device Utilization Summary } \\
\hline Logic Utilization & Used & Available & Utilization & Note(s) \\
\hline Number of Slice Flip Flops & 32 & 9,312 & $1 \%$ & \\
\hline Number of 4 input LUTs & 61 & 9,312 & $1 \%$ & \\
\hline Number of occupied Slices & 31 & 4,656 & $1 \%$ & \\
\hline Number of Slices containing only related logic & 31 & 31 & $100 \%$ & \\
\hline Number of Slices containing unrelated logic & 0 & 31 & $0 \%$ & \\
\hline Total Number of 4 input LUTs & 61 & 9,312 & $1 \%$ & \\
\hline Number of bonded IOBs & 35 & 232 & $15 \%$ & \\
\hline Number of BUFGMUXs & 1 & 24 & $4 \%$ & \\
\hline Average Fanout of Non-Clock Nets & 3.38 & & & \\
\hline
\end{tabular}

FIG. 15. SUMMARY REPORT OF THE PROPOSED FPGA-PID CONTROLLER.

The hardware description language functional model is generating verilog file that is extracted to the black box using the Xillinx-system generator in the MATLAB environment. The black box with the ports Gateway In and Gateway Out shown in Fig. 16; is tested with the overall fuel cell system under MATLAB environment before downloading. This black box is used to download the bit stream of the proposed FPGA-PID controller on the Spartan-3E Starter Kit with device xc3s500e-4fg320 using the system generator through the JTAG (Joint-Test-Action-Group) as an interface and by the USB (universal serial bus) cable.The downloading process is done by using the hardware co-simulation mechanism. This mechanism enables the building of the hardware form for the designed controller.

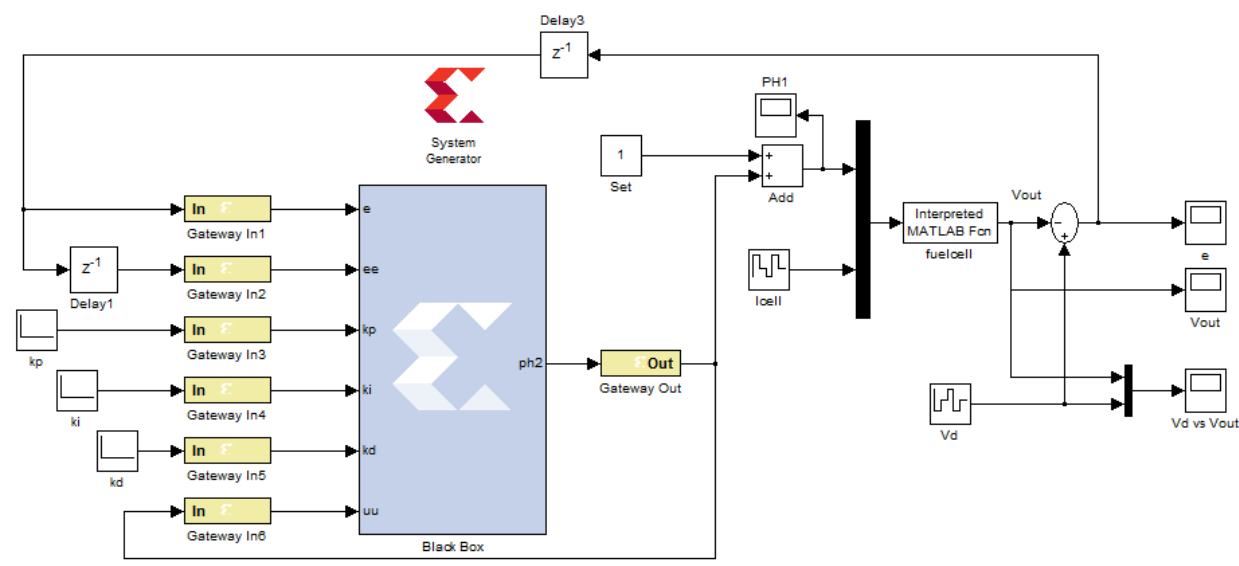

FIG. 16. THE BLACK BOX BASED ON XILINX SYSTEM GENERATOR.

First, and from the HDL netlist the chosen name for the used kit is selected. A compilation status was shown when starting the generating of a co-simulation block. Through the compilation process a generating, performing, synthesizing and running XFlow were done with no errors. After completing the compilation process successfully, a JTAG block was generated as shown in Fig. 17.

The JTAG hwcosim (hardware co-simulation) interface block makes interaction with Spartan-3E Starter Kit with device xc3s500e-4fg320 during the system simulation running; it passes the incoming data from the system to the FPGA kit through the Gateway Ins while the FPGA kit sends the output (control signal) to the fuel cell system through the Gateway Out of the JTAG block. Therefore, the 
block diagram of the proposed FPGA-PID controller for fuel cell model in the real time is represented in Figs. 18 a, b.

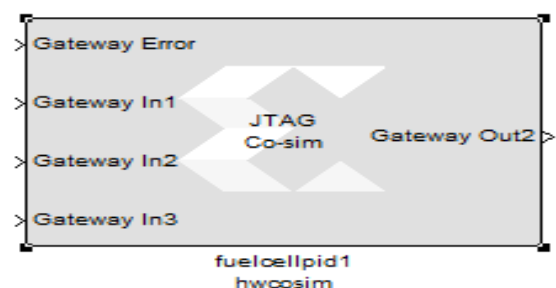

FIG. 17. JTAG BLOCK WAS GENERATING.

In the real time MATLAB Simulink environment with system generator that is used for controlling and monitoring the experimental results for the adaptive FPGA-PID controller for the fuel cell system, Fig. 19; shows the fast response of the actual output voltage of the fuel cell in the five desired voltage steps with very small overshoots after 50 samples and the voltage error of the fuel cell system at steadystate is equal to zero. Fig. 20; illustrates the high performance of digital FPGA-PID controller in terms of fast generating digital partial pressure $\left(\mathrm{PH}_{2}\right)$ control action for tracking voltage error of the fuel cell system
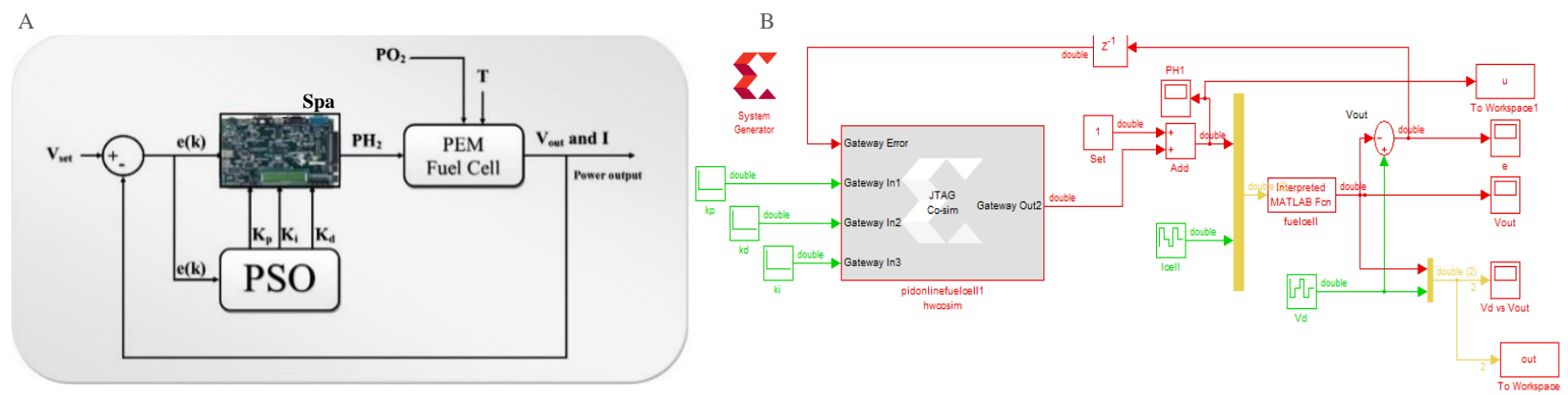

FIG. 18 A) THE EMULATOR BLOCK DIAGRAM OF THE PROPOSED FPGA-PID CONTROLLER IN THE REAL TIME; B) MATLAB SIMULINK ENVIRONMENT WITH SYSTEM GENERATOR.

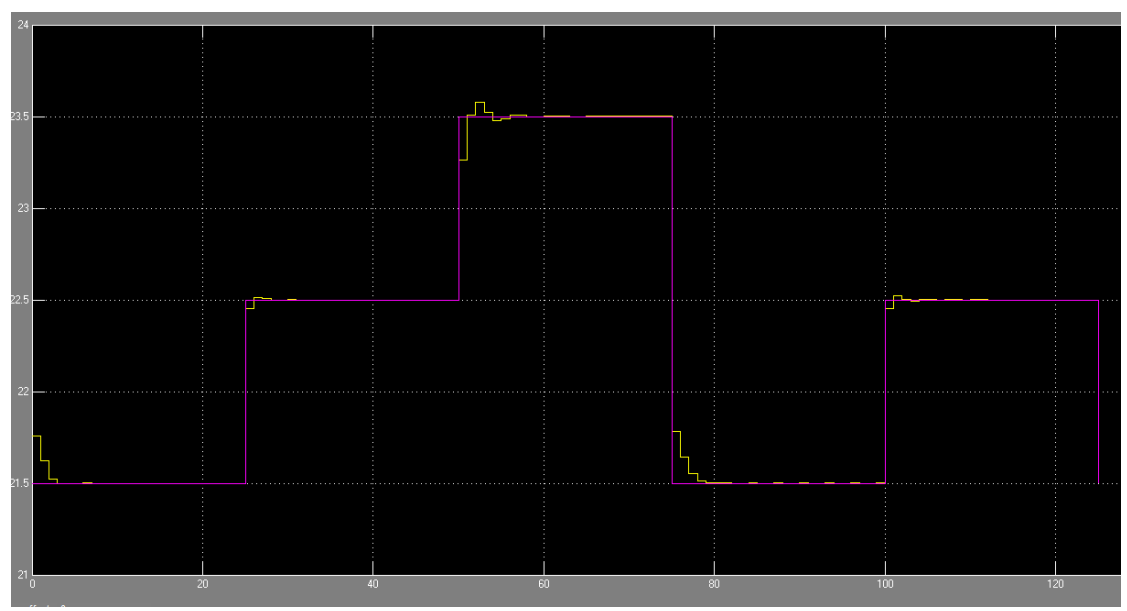

FIG. 19. THE RESPONSE OF THE ACTUAL OUTPUT VOLTAGE OF THE FUEL CELL IN THE FIVE DESIRED VOLTAGE STEPS. 


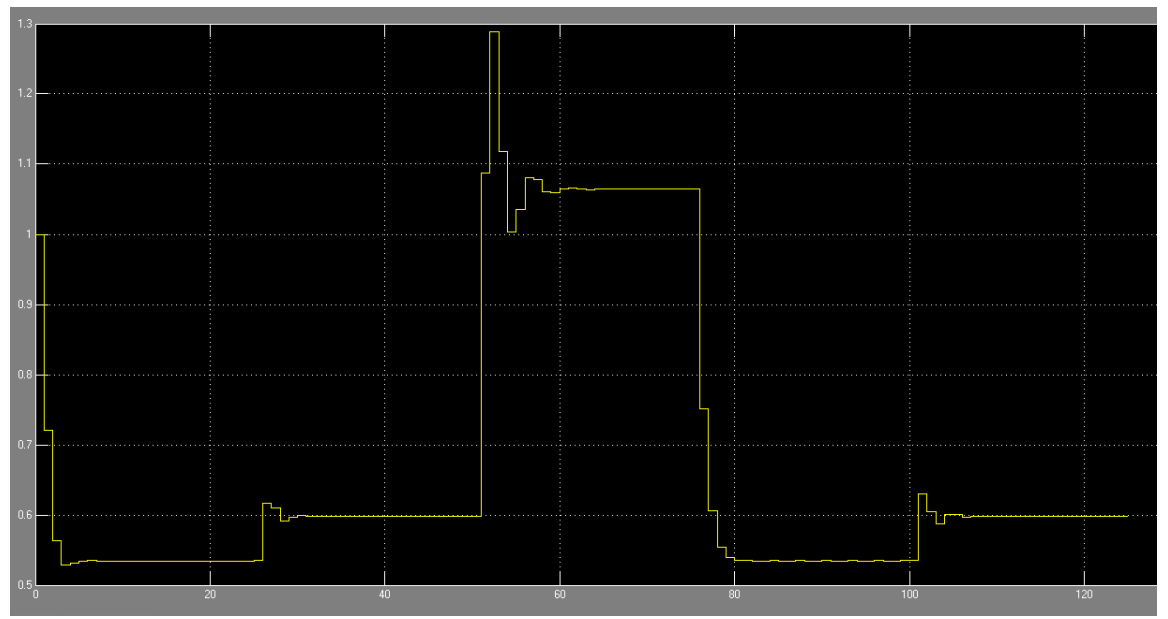

FIG. 20. THE HYDROGEN PARTIAL PRESSURE CONTROL ACTION OF DIGITAL FPGA-PID.

\section{CONCLUSIONS}

In this paper, an off-line adaptive FPGA-PID controller with intelligent PSO tuning algorithm for fuel cell system have been designed and simulated for different desired output voltage with variable load current using real-time MATLAB Simulink environment. The Spartan-3E board with device xc3s500e-4fg320 and ISE for Xilinx development tool have been used to make the schematic proposed controller design, simulate and verify for fuel cell system after converting the proposed adaptive continuous control law equation to the proposed adaptive digital control law equation. From the simulation and experimental results, a comaprison of the digital proposed controller and other control methodology show that the performance of the proposed digital FPGA-PID controller is much more efficient in terms of the following:

- The actual output voltage reached the desired voltage faster without oscillation during variable load current.

- The tracking voltage error has been approximately reached to zero value.

- Smooth partial pressure $\left(\mathrm{PH}_{2}\right)$ control action which was generated with small spikes and no saturation state ; therefore, the proposed controller has the ability to track the desired voltage with high precision.

- Only three stable positive values of the gain control parameters are used with an off-line PSO tuning algorithm that led to stabilize both the digital control action $\left(\mathrm{PH}_{2}\right)$ response and the fuel cell output voltage performance.

\section{REFERENCES}

[1] W. T. Al-Rubaye, A. S. Al-Araji, and H. A. Dhahad, "Numerical Simulation based Modeling and Analysis of Fuel Cell System". International Journal of Science and Research (IJSR), vol. 9, no. 5, pp. 1044-1048, 2020.

[2] A. Al-Araji, H. Dhahad, and E. Jaber, "A Neural Networks based Predictive Voltage-Tracking Controller Design for Proton Exchange Membrane Fuel Cell Model”. Journal of Engineering, vol. 25, no. 12, pp. 26-48, 2019.

[3] C. Spiegel, "PEM Fuel Cell Modeling and Simulation using MATLAB". Elsevier, 2011.

[4] F. Barbir, "PEM Fuel Cells: Theory and Practice". Academic Press, 2012.

[5] S. Mekhilef, R. Saidur, and A. Safari, "Comparative Study of Different Fuel Cell Technologies". Renewable and Sustainable Energy Reviews, vol. 16, no. 1, pp. 981-989, 2012.

[6] W. Daud, R. Rosli, E. Majlan, S. Hamid, R. Mohamed, and T. Husaini, "PEM Fuel Cell System Control: A Review". Renewable Energy, vol. 113, pp. 620-638, 2017. 
[7] K. E. Dagher, "Design of an Adaptive Neural Voltage-Tracking Controller for Nonlinear Proton Exchange Membrane Fuel Cell System based on Optimization Algorithms". Journal of Engineering and Applied Sciences. vol. 13, no. 15, pp. 6188-6198, 2018.

[8] A. Rezazadeh, A. Askarzadeh, M. Sedighizadeh, "Adaptive Inverse Control of Proton Exchange Membrane Fuel Cell using RBF Neural Network". International Journal of electrochemical science, vol. 6, pp. 3105-3117, 2011.

[9] M. Ali, A. Abudhahir, A. Manivanna Boopathi, "Sliding Mode Controller for Pressure Regulation in PEM Fuel Cell”. Journal of Communications Technology, Electronics and Computer Science, vol. 15, pp. 5-15, 2017.

[10] Y. A. Zúñiga-Ventura, D. Langarica-Córdoba, J. Leyva-Ramos, L. H. Díaz-Saldierna, V. Ramírez-Rivera, “Adaptive Back-stepping Control for a Fuel Cell / Boost Converter System”. IEEE Journal of Emerging and Selected Topics in Power Electronics, vol. 6, no. 2, pp. 686-695, 2018.

[11] J. Schumacher, P. Gemmar, M. Denne, M. Zedda, and M. Stueber, "Control of Miniature Proton Exchange Membrane Fuel Cells based on Fuzzy Logic”. Journal of Power Sources, vol. 129, no. 2, pp. 143-151, 2004.

[12] K. Mammar, and A. Chaker, "Fuzzy Logic-based Control of Power of PEM Fuel Cell System for Residential Application”. Leonardo J, vol. 14, pp. 147-166, 2009.

[13] H. Beirami, A. Z. Shabestari, and M. Zerafat, "Optimal PID plus Fuzzy Controller Design for a PEM Fuel Cell Air Feed System using the Self-Adaptive Differential Evolution Algorithm”. International journal of hydrogen energy, vol. 40, no. 30, pp. 9422-9434, 2015.

[14] M. El-Sharkh, A. Rahman, and M. Alam, "Neural Networks-based Control of Active and Reactive Power of a StandAlone PEM Fuel Cell Power Plant”. Journal of Power Sources, vol. 135, no. 1-2, pp. 88-94, 2004.

[15] K. Mammar, and AChaker, "Neural Network-Based Modeling of PEM Fuel Cell and Controller Synthesis of a StandAlone System for Residential Application”. International Journal of Computer Science Issues (IJCSI), vol. 9, no. 6, pp. 244, 2012.

[16] N. Rajasekar, B. Jacob, K. Balasubramanian, K. Priya, K. Sangeetha, and T. Babu, "Comparative Study of PEM Fuel Cell Parameter Extraction using Genetic Algorithm”. Ain Shams Engineering Journal, vol. 6, no. 4, pp. 1187-1194, 2015.

[17] Y. Ren, Z. D. Zhong, H. X. Liu, and X. H. Wang, "Particle Swarm Optimization for Identification of PEMFC Generation System Fuzzy Model". In Advanced Materials Research, vol. 588, pp. 260-263.

[18] A. Abdelaziz, S. Mekhamer, M. Badr, and M. Algabalawy, "The Firefly Metaheuristic Algorithms: Developments and Applications”. International Electrical Engineering Journal (IEEJ), vol. 6, no. 7, pp. 1945-1952, 2015.

[19] S. Asl, S. Rowshanzamir, and M. Eikani, "Modelling and Simulation of the Steady-State and Dynamic Behaviour of a PEM Fuel Cell”. Energy, vol. 35, no. 4, pp. 1633-1646, 2010.

[20] A. Al-Araji, "Genetic Algorithm and Elman Neural Network used for Tuning the Parameters of the PID Neural Controller based Model Reference". Iraqi Journal of Computers, Communication and Control \& Systems Engineering, vol. 5, no. 1, pp. 111-126, 2005.

[21] A. Al-Araji, "Applying Cognitive Methodology in Designing On-Line Auto-Tuning Robust PID Controller for the Real Heating System”. Journal of Engineering, vol. 20, no. 9, pp. 43-61, 2014.

[22] A. S. Al-Araji, "Design of On-Line Nonlinear Kinematic Trajectory Tracking Controller for Mobile Robot based on Optimal Back-Stepping Technique". Iraqi Journal of Computers, Communication and Control \& Systems Engineering, vol. 14, no. 2, pp. 24-36, 2014.

[23] A. Al-Araji, "Development of an On-Line Self-Tuning FPGA-PID-PWM Control Algorithm Design for DC-DC Buck Converter in Mobile Applications". Journal of Engineering, vol. 23, no. 8, pp. 84-106, 2017.

[24] D. Williamson, "Digital control and implementation". Prentice Hall PTR, 1991.

[25] A. A. Khedkar, R. J. M. Khade, "High Speed FPGA-based Data Acquisition System". Microprocessors and Microsystems, vol. 49, pp. 87-94, 2017. 